\title{
Isolated hoffa fracture - an unusual and commonly forgotten fracture
}

\begin{abstract}
Hoffa fractures are known as coronal fractures of the femoral condyle and are rare injuries - account for less than $1 \%$ of distal femur fractures. It is an intraarticular fracture of the posterior aspect of the femoral condyle in coronal plane, resulting from high-energy traumas - motor vehicle accidents (most common) or a fall from a height. Inherently unstable, due to bone instability, as well as the pull of the gastrocnemius and popliteus. Fractures of the medial and lateral condyle tend to heal with a varus and valgus deformity, respectively. The Hoffa fracture of the lateral femoral condyle is more common than the medial side rarely the patient present with bicondylar fracture. The physician should always look for associated injuries of the pelvis, hip, patela and tibial plateau fractures, popliteal vessel injuries and ligamentous disruptions of the knee. The authors report a case with computed tomography and radiographic diagnosis of this unusual fracture.
\end{abstract}

Keywords: Femoral Fractures, Diagnostic imaging, Femoral Fractures/surgery, Knee Injuries/surgery, Accidents, Traffic
Volume 10 Issue 2 - 2018

\author{
Márcio Luís Duarte,' Caio Eduardo Ferreira \\ Rezieri, ${ }^{2}$ Maura Harumi Ito,' Bruno Barros \\ Fernandes Brehme de Abreu,' Thiago Ribeiro \\ dos Santos, ${ }^{2}$ Maurício Wanderley Moral \\ Sgarbi ${ }^{2}$ \\ 'Radiology,WEBIMAGEM, Brazil \\ ${ }^{2}$ Orthopedics, Irmandade da Santos Casa da Misericordia de \\ Santos, Brazil
}

Correspondence: Marcio Luis Duarte, WEBIMAGEM, Avenida Marques de Sao Vicente 446, Sao Paulo, Sao Paulo, Brazil, Email marcioluisdurate@gmail.com

Received: November 24, 2017 | Published: January 17, 2018

\section{Introduction}

Hoffa fractures are known as coronal fractures of the femoral condyle and are rare injuries - account for less than $1 \%$ of distal femur fractures. ${ }^{1-4}$ The association of Hoffa fracture and proximal tibial fractures is even rarer. ${ }^{5}$ It is an intraarticular fracture of the posterior aspect of the femoral condyle in coronal plane, resulting from highenergy traumas - motor vehicle accidents (most common) or a fall from a height. ${ }^{1,4,6}$ Inherently unstable, due to bone instability as well as the pull of the gastrocnemius and popliteus. ${ }^{1,5}$

The exact mechanism of this injury is unknown, ${ }^{1,5,6}$ but it has been postulated that the mechanism of injury is axial compression to the knee with transmission of the ground reaction force through the tibial plateau to the femoral condyles - in a flexed position the posterior portion of the lateral condyle is the leading part of the knee receiving the impact. ${ }^{3}$

\section{Case presentation}

32-years-old man with direct trauma on the right knee after motorcycle accident referring severe pain in the knee, making physical examination impossible.

Radiograph of the right knee showed fracture of the posterior aspect of the lateral femoral condyle - Hoffa fracture - type II (Figure 1). CT scan shows fracture of the lateral femoral condyle with a slight misalignment and separation of the fragment, which indicated surgery (Figures $1 \& 2$ ). The patient was discharged after surgery, attending since the being accompanied ambulatorially since then (Figure 3 ).

\section{Discussion}

Fractures of the medial and lateral condyle tend to heal with a varus and valgus deformity, respectively. ${ }^{1,2}$ The Hoffa fracture of the lateral femoral condyle is more common than the medial side - rarely the patient present with bicondylar fracture..$^{5,7,8}$ Do not present, so far, a pseudoarthrosis percentage. ${ }^{2} 2$

Hoffa fracture is classified into three types by Letenneur ${ }^{6}$

Type I: vertical fracture involving the entire condyle parallel to the posterior cortex of the femur.
Type II: variable size of the fracture and is horizontal to the base of the condyle.

Type III: is a fracture oblique to the femur, originally described for lateral Hoffa fracture.
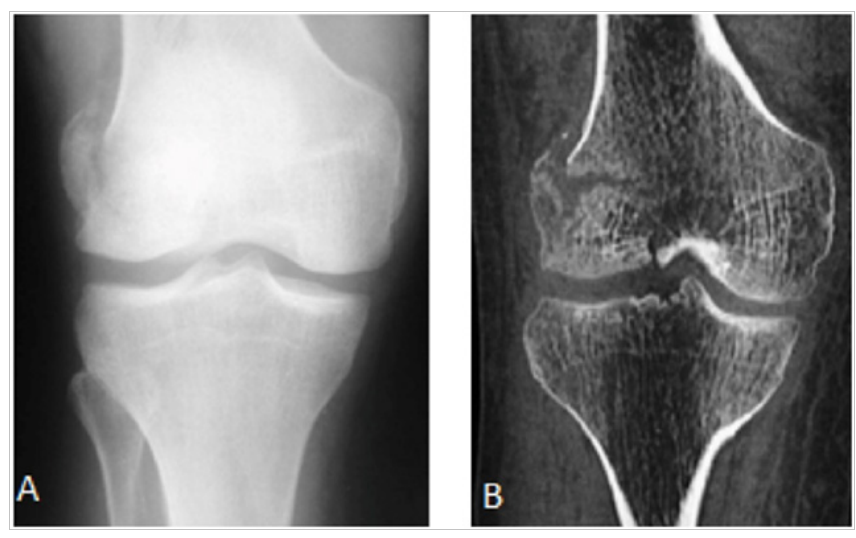

Figure I In A, anteroposterior radiograph and CT scan coronal section in $\mathrm{B}$ demonstrating fracture of the lateral femoral condyle with a slight misalignment and separation of the fragment.
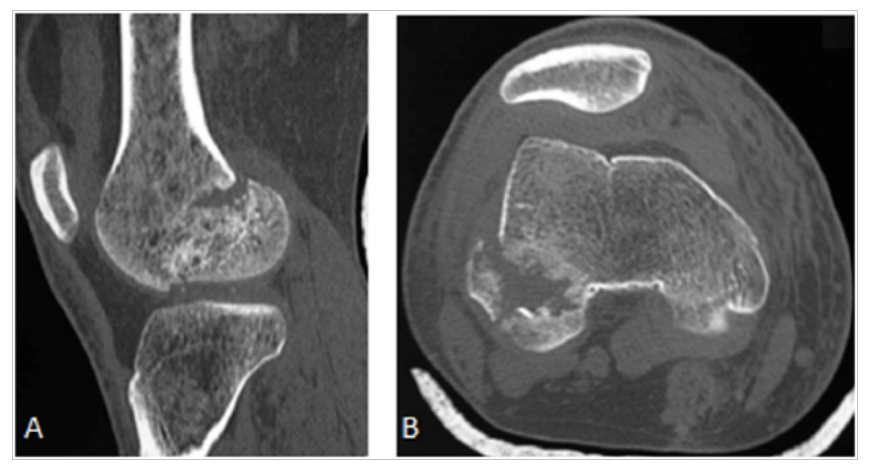

Figure 2 CT scan in sagital section in A and axial section in shows fracture of the lateral femoral condyle with a slight misalignment and separation of the fragment, which indicated surgery. 

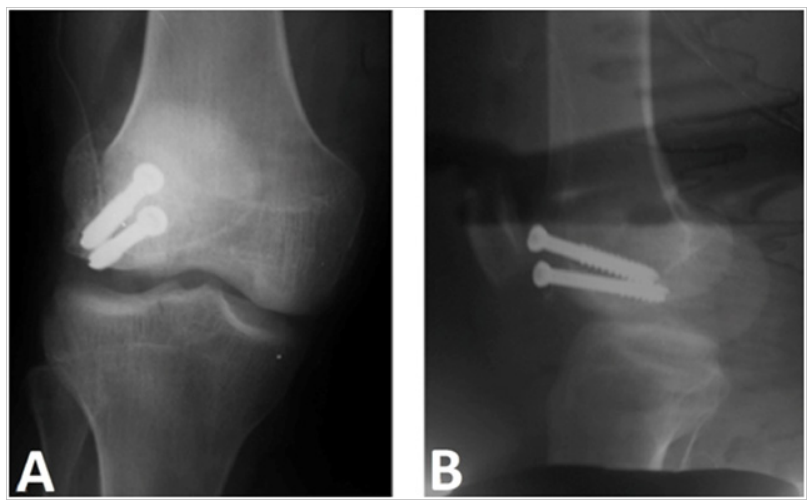

Figure 3 In A, anteroposterior radiograph and in B, lateral radiograph, demonstrating postoperative synthesis of the lateral femoral condyle fracture with two cannulated screws for large fragments.

Often missed on plain radiographs but easily found on a CT scan, helping the preoperative planning. ${ }^{1,-8} \mathrm{Up}$ to $25-30 \%$ of coronal plane fractures can be missed on plain radiographs., ${ }^{5,7}$ The presence of a supracondylar fracture with intraarticular extension suggests that there may be an occult associated coronal-plane Hoffa fracture. ${ }^{7}$

CT scan is extremely helpful in characterization of complex intraarticular fractures of the distal femur. ${ }^{4,7}$ The physician should always look for associated injuries of the pelvis, hip, patela and tibial plateau fractures, popliteal vessel injuries and ligamentous disruptions of the knee $^{7}$ magnetic resonance imaging is useful for this search. ${ }^{6}$

The management goal for all types of intra-articular fractures is to achieve anatomical reduction and adequate stability enabling early mobilization. ${ }^{3}$ Non-operative treatment of Hoffa fractures leads to malunion, nonunion, displacement of the fracture fragment and stiff knee. ${ }^{4,5}$ Literature review reveals that there is no consensus on the surgical approach and the implants to be used for treatment of Hoffa's fracture. ${ }^{8}$ Problems of this surgical approach are infectious hazards, devascularization also fragment necrosis. Nowadays treatment with endoscopic mini invasive (arthroscopic) surgery may reduce its risk. ${ }^{4}$

Physicians should be very careful to diagnosis the Hoffa fracture on radiographs. However, in some cases, it cannot be characterized by such method, requiring the CT scan for complementation.

\section{Acknowledgements}

Not applicable.

\section{Conflicts of interest}

The authors declare that there is no conflict of interests regarding the publication of this paper.

\section{Patient consent}

The written informed consent of the patient was obtained, for the publication of her case.

\section{References}

1. Jiang YR, Wang ZY, Zhang DB, et al. Twenty-seven-year nonunion of a Hoffa fracture in a 46-year-old patient. Chin J Traumatol. 2015; 18(1):54-58.

2. Albuquerque RP, Giordano V, Amaral NP, et al. Artroplastia total do joelho em paciente com pseudoartrose de fratura de Hoffa: Relato de Caso. Ver Bras Ortop. 2011;46(4):460-462.

3. Cheng PL, Choi SH, Hsu YC. Hoffa fracture: should precautions be taken during during fixation and rehabilitation? Hong Kong Med J. 2009;15(5):385-387.

4. Koné S, Bana A, Touré SA, et al. Hoffa fracture of medial unicondylar and bilateral in a man: a rare case. Pan Afr Med J. 2015;20:382.

5. Jain A, Aggarwal P, Pankaj A. Concomitant ipsilateral proximal tíbia and femoral Hoffa fractures. Acta Orthop Traumatol Turc. 2014;48(4):383-387.

6. Gao M, Tao J, Zhou Z, et al. Surgical treatment of medial Hoffa fracture fixed by locking plate and additional screws: A retrospective cohort study. Int J Surg. 2015;19:95-102.

7. Baker BJ, Escobedo EM, Nork SE, et al. Hoffa fracture: a common association with high-energy supracondylar fractures of the distal femur. AJR Am J Roentgenol. 2002;178(4):994.

8. Jain SK, Jadaan M, Rahall E. Hoffa's fracture - lateral meniscus obstructing the fracture reduction - a case report. Injury. 2015;46(2):419-421. 